\title{
CRITICAL APPROACH TO THE ALTERNATIVE TREATMENT OF CHRONIC KIDNEY DISEASE IN DOGS AND CATS
}

\author{
Jeff M. Pérez ${ }^{1,2 *}$, Chiara Alessi ${ }^{1}$ \\ ${ }^{1}$ Department of Animal health, University of Caldas, C.P: 170004, Street65, No 26-10, Manizales, ${ }^{2}$ Cuor-Tech ${ }^{\mathrm{TM}}$ Sport Medicine and Veterinary \\ Cardiology Service, C.P 660006, Pereira, Colombia \\ *Corresponding author, E-mail: jeff.mp@outlook.com
}

\begin{abstract}
Chronic kidney disease (CKD) is common in dogs and cats and can occur at any age, especially in geriatric animals. The various presentations of the disease and their different hemodynamic and metabolic alterations are issues of profound research. Currently clinicians improvements of the comprehensive management of chronic kidney disease focuses on the delay of the progression of clinical signs of the disease and there now are numerous novel methods that also were proposed to slow the progression of the disease, with the possibility of use in non-referral centers. The aim of this critical approach is to provide an overview of the comprehensive treatment of chronic kidney disease, expose new treatments that could improve the intervention of dogs and cats with chronic kidney disease and reevaluate the usefulness of some existing drugs.
\end{abstract}

Key words: chronic kidney disease; cardiorenal syndrome; glomerulonephritis; dog; cat

\section{Introduction}

Chronic kidney disease (CKD) is a common disease in dogs and cats with greater prevalence in geriatric animals, although it can occur at any age and its incidence in the general dogs and cats population is approximately 0.5 and $4.5 \%$, respectively (1-3). CKD is defined as an structural and/or functional disability in one or both kidneys present for more than 3 months (2, 4) and their main features are deteriorated renal excretion and decreased glomerular filtration rate

Received:28 July 2016

Accepted for publication: 14 July 2017
(GFR) (5). In addition, endocrine and biosynthetic functions are progressively altered (3). Dialysis and kidney transplantation are still only performed in reference centers and sometimes are not feasible procedures for the owner. Despite medical treatment continues to be invaluable to slow the progression of the disease, nutritional modification is one of the most important factors that influence the metabolic imbalances and is a determining factor in the health-related quality of life of affected patients (6). Thus, in human and veterinary medicine, poor body condition has been associated with decreased health-related quality of life and survival time $(7,8)$. 
The clinical presentation of the disease, the early diagnosis and the comprehensive treatment are a medical challenge that needs individual strategies due to the great variability between different patients and diverse clinical presentation. The goals of medical treatment of CKD are to slow down the progression of the disease, prevent complications caused by decreased renal function and control the clinical signs of uremia. It is also critical to stabilize the biosynthetic process and correct non-renal diseases that may decompensate patients with CKD such as diarrhea, vomiting and dehydration. Sometimes secondary endocrine disruption of CKD is neglected because of purely renal approaches that usually take place $(2,3)$. The aim of this critical approach is to present the progress in recent years in the comprehensive treatment of CKD. In addition, it aims to provide a different perspective, in terms of treatments that have existed during the past decade and those medical and / or pharmacological implications that might have changed.

\section{Nutritional Intervention}

\section{The Critical Role of Nutrition}

One of the main signs that present dogs and especially cats with kidney dysfunction is the loss of appetite. Thus, nutritional intervention is always required, considering that decreasing the presentation of many complications related to functional deficiency of the kidney (p.e uremic syndrome, hyperparathyroidism and anemia), improve coming through in health-related quality of life and survival time (8). The specific targets of the nutritional modification are to prevent uremic syndrome, maintain acid-base control, correct electrolyte imbalances and slow down the progression of CKD. In addition, this diets provide water-soluble vitamins and minerals supplement for maintain a balance between nutritional requirements and the necessary dietary restrictions $(2,3,9)$. Nevertheless, the primary goal of nutritional therapy is to maintain stable body condition and muscle mass. These therapeutic strategies are more effective combined with focused therapies that directly correct the progression of specified etiology of CKD (such as nephrotic syndrome, hypercalcemia, renal disease, urinary tract infection, chronic urinary tract obstruction, glomerulonephropathies and immune-mediated disease, etc.) $(9,10)$.

To initiate the nutritional modification, experts have recommended correcting first the clinical signs of uremia (11). The evidence-based medicine is the most important factor in the management of the CKD (12), many studies have demonstrated the implications of nutritional therapy and renal diets typically have low levels of protein, sodium, and phosphorus. But also, high levels of antioxidants, polyunsaturated fatty acids (Omega 3 and 6) and water soluble vitamins, fiber and more energy density (13-16). Renal diets statistically decrease $72 \%$ of the relative risk of uremic crisis in cats (9). In the same way, renal diets in canines allows to remain 2.5 times longer without showing signs of uremia in this species (7), demonstrating that only with renal diet, disease progression is slower $(6,13)$. Although there are few research about this topic, the health-related quality of life and life expectancy significantly improves with the nutritional management (16).

\section{Modulation of inflammation and Oxidative stress}

A variety of benefits have been attributed to supplementation with polyunsaturated fatty acids (PUFA's), including its tendency to decrease cholesterol, modulation of inflammation and control of blood pressure $(17,18)$. In human patients with renal disease, improvement in glomerular renal circulation and decreased calcification has also been recognized with this supplementation (19). One review published by Roudebush and colleagues (9) found that injuries such as glomerulosclerosis, tubulointerstitial fibrosis and infiltration of pro-inflammatory cells decreased significantly in dogs diets supplemented with PUFA's.

Oxidative stress caused by free radicals generation and reactive oxygen species can cause kidney damage accelerate the progression of CKD (20). Yu et al (21) found that antioxidant supplementation significantly reduced oxidative stress and plasma creatinine levels compared with dogs receiving a diet without antioxidants. Other research in dogs with induced CKD showed that the nutritional supplementation with omega-3 and antioxidants (p.e vitamin E, 
carotenoids and lutein) were independently reno-protective and its effect was additive when used together (22). However, at the time metaanalysis or cohort studies were not published to determine if PUFA's have clinical value in representative populations of dogs or cats and further investigations are expected.

\section{Chronic Kidney Disease-mineral Bone Disorder}

The mechanism of excretion and control of phosphorus is normally composed of glomerular filtration and tubular reabsorption $(23,24)$. During CKD glomerular filtration rate decreases and phosphorus is retained, then tubular reabsorption of Phosphorus increases as a countervailing mechanism of "false" decreasing in the amount of phosphorus reaching the tubule lumen, which ends with the development of hyperphosphatemia and all its related aberrations, especially hormonal imbalance responsible of mineral equilibrium (see figure 1) (25). Hyperphosphatemia plays an important role in the development of secondary hyperparathyroidism in CKD. There is now appropriated evidence to recommend diets with restriction of phosphorus in kidney-affected patients $(10,26,27)$.

In patients with advanced stages of renal dysfunction (IRIS III-IV), the restriction of phosphorus in the diet alone does not prevent hyperphosphatemia (28). Using phosphorus binders (p.e hydroxide aluminum) would be of help at least in dogs. It should be said that some patients cannot tolerate the intake of hydroxide aluminum and no serious investigations were published with a good level of evidence that allow its recommendation in clinical practice. A new oral phosphate binder SBR759 (Lenziaren ${ }^{\circledR}$ ) was developed and evaluated by King (28) with favorable results in acceptability, clinical improves, tolerability and safety in cats. However, further evidence is needed to prove the real clinical benefit.

Calcitriol is the hormone responsible of renal calcium metabolism (23). Kidney converts the 25-hydroxycholecalciferol by the enzyme hydroxylase 1 alpha, to the active metabolite 1 , 25-Dihidroxicolecalficerol (Calcitriol). Thus, in turn has a relationship with the modulation of parathyroid hormone. Because the CKD may be associated with decreased production of 1 , 25-dihydroxycholecalciferol, this deficiency can promote hyperplasia of the parathyroid gland, alteration known as secondary hyperparathyroidism to CKD (27). Calcitriol supplementation may decrease a variety of complications attributed to the excess parathyroid hormone (PTH) levels in kidney-affected patients (26) and research suggests that calcitriol therapy prolongs survival time in dogs $(26,27,29)$. The authors recommend caution in this topic and waited for further research to define a possible overall conclusion.

\section{Hyperkalemia in CKD}

The electrolytes disturbance, especially alteration of potassium (Hyperkalemia) is common in dogs with CKD. Although they are of common incidence in acute complications it has a critical role in the final stages of the disease (30). In addition, there is the possibility that the amount of potassium in the diet exceeds renal excretion resulting in hyperkalemia in some patients. In humans with primary renal disease, the use of angiotensin converting enzyme inhibitors (ACEI's) can have complications such as hyperkalemia (31). Although disagreement exist and little evidence in canine and feline patients, there may be also a moderate or similar risk to present hyperkalemia.

One Research done by Segev and colleagues (32) showed that hyperkalemia is a potential complication of CKD in dogs that consumed a commercial therapeutic diet. Nevertheless, this investigation apparently found no relationship between the administration of ACEI's and serum potassium levels in the study population. In addition, canines that require hemodialysis are prone to develop severe hyperkalemia and the point-of-care testing of electrolytes should be applied during the procedure (33). Finally, it is important to take into account that depending on the stage of the disease, each patient should receive an individual treatment and nutritional therapy corresponding to renal function, considering that one diet for a patient with stage IRIS II-III, cannot necessarily be identical to an IRIS patient IV (see table 1)(6). 
Figure 1: Chronic kidney disease-mineral and bone disorder is charactericed by PO4 retention as a consequence of declining GFR. FGF-23 increases in response to PO4 accumulation, but inhibits renal 1-a-hydroxilase and then decreases calcitriol levels. Hight calcitriol levels inhibit PTH synthesis and without this feedback inhibition, PTH increases. Other consequences of lower calcitriol levels are the increase of skeletal resistance to PTH action and the limitation of the Ca-induced suppression of PTH secretion. PTH secretion continue due to the fact that coreceptors klotho are diminished in the parathyroid gland. Impaired gastro-intestinal absorption of $\mathrm{Ca}$ due to low levels of calcitriol is another negative consequence. The liver, lung, heart and blood vessels are prone to the development of calcinosis and loss of function. The cardiorenal syndrome type IV is known as the impact of CKD on heart and vessels function and is recently reviewed in small animals. (Figure credit: Chiara Alessi)

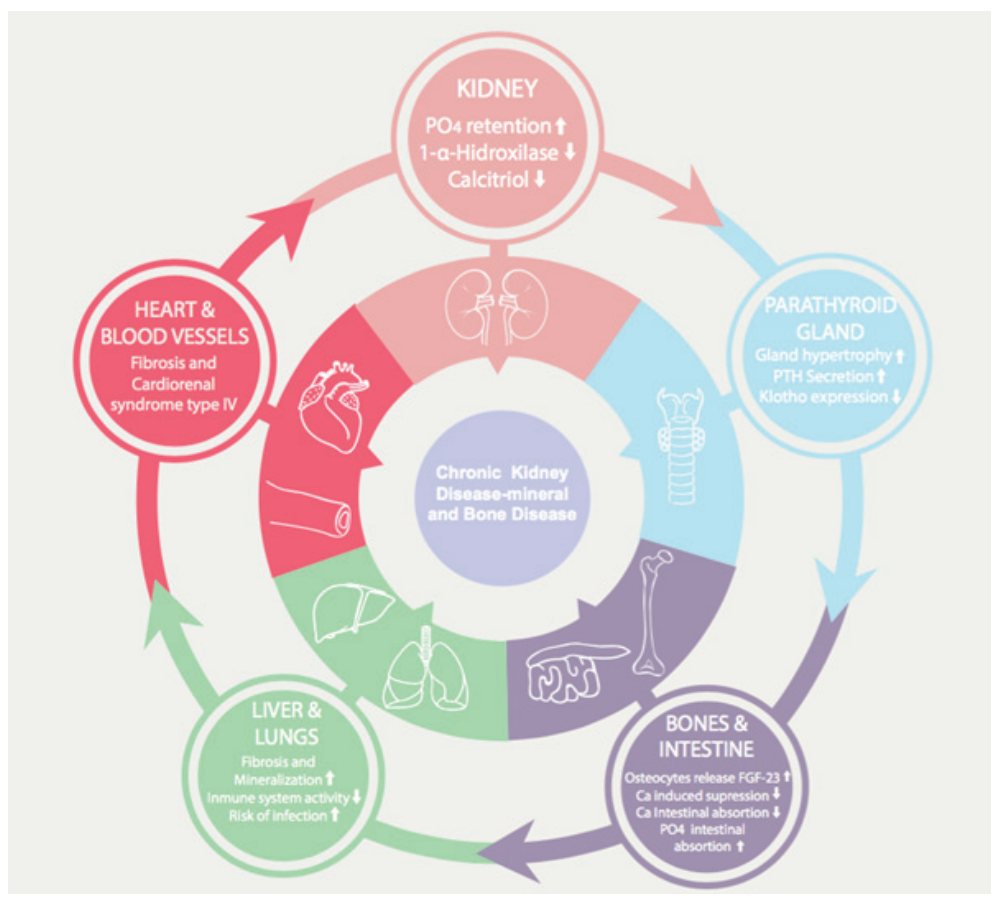

Table 1: The CKD stratification system has been proposed by the International Renal Interest Society (IRIS) to help provide guidelines for clinical management of CKD. Staging is based on serum creatinine values, with substages identified for blood pressure and proteinuria. Taken and modified from (Foster JD. Canine chronic kidney disease current diagnostic and long-term management. Today's Veterinary Practice, September/October 2013)

\section{CKD IRIS Staging System}

\begin{tabular}{lll}
\hline Serum Creatinine $\mathbf{~ m g / d 1}$ & Dogs & Cats \\
\hline Stage I & $<1.4$ & $<1.6$ \\
\hline Stage II & $1.4-2$ & $1.6-2.8$ \\
\hline Stage III & $2.1-5$ & $2-5$ \\
\hline Stage IV & $>5$ & $>5$ \\
\hline
\end{tabular}

\section{Getting to the extremes}

Both anorexia and malnutrition are the most critical clinical complications in CKD of dogs and cats if it takes take into account their contribution on morbidity and mortality $(6,7)$. Sometimes assisted feeding should be provided in order to minimize the risk of uremic crisis or death because it allows the feeding and prevents long periods without nutrition or liquid consumption $(34,35)$. The first step is to ensure that lost of appetite is due to syndromes that increase metabolic complications such as dehydration states, gastrointestinal bleeding, metabolic acidosis, hypokalemia or urinary tract infection. When these possible causes have been excluded or corrected and no improvement is seen in appetite, it is recommended to intervene. For example gastrointestinal complications are routinely treated with the administration of $\mathrm{H} 2$ antagonists (p.e famotidine $0.5 \mathrm{mg} / \mathrm{kg} \mathrm{q} 12 \mathrm{~h} \mathrm{PO}$ ), antiemetics (Maropitant citrate $1 \mathrm{mg} / \mathrm{kg}$ q24h S.C) and gastric mucous protectors (sucralfate 40 $-250 \mathrm{mg} / \mathrm{kg}$ q12h P.O). Isolated reports suggest that the placement of a feeding tube can reduce weight loss associated with CKD (34). However, their implications for health-related quality of life and long-term outcomes are still undefined. 


\section{Endocrine disturbances and conservative advanced therapies}

\section{Hormone replacement and Anemia}

The decrease in red blood cells count, percentage of hematocrit and hemoglobin is common in dogs and cats with CKD in stage IRIS III-IV (2). In kidney-affected patients the main cause of anemia is hypoplasia of erythroid elements secondary to inadequate production of erythropoietin (EPO) in the renal marrow and is exacerbated by the short life of the erythrocytes due to azotemia, acid-base disorders, the premature apoptosis, gastrointestinal bleeding, nutritional disorders, iron deficiency and bone marrow fibrosis (36-38). Erythropoietin hormone replacement usually leads to develop with recombinant human alpha EPO in dogs (rHuEPO; Epogen ${ }^{\circledR}$ Amgen, Thousand Oaks, CA, USA). This is highly effective but with shortlive in bloodstream (39). Recent research has revealed that dogs with CKD and anemia treated with rHuEPO stabilize the hematocrit levels, the augmentation in appetite was also evidenced and health-related quality of life then improving (9). Unfortunately, the development of antibodies against rHuEPO in dogs and cats has limited its use to a minor amount of the population and therefore, the use of rHuEPO should be limited to patients with less than 22 or $20 \%$ hematocrit and signs of anemia like hypoxemia, exercise intolerance, cyanosis or heart murmurs.

Although little research has been done in veterinary medicine, darbepoetin alpha it may be less immunogenic compared with rHuEPO (40). $\mathrm{Lu}$ and colleagues (41) evaluated the efficacy and safety of recombinant canine erythropoietin (rCaEPO) in dogs with non-regenerative anemia secondary to CKD. They found that in dogs receiving $\mathrm{rCaEPO}$, a slightly increased erythrocyte production was evident. In addition, there was hyperplasia in bone marrow, reticulocytosis, normal levels of hematocrit and direct improving of health-related quality of life. In contrast, complications related to the creation of antirCaEPO antibodies were very low. Furthermore, it should be known that hypertension is a complication in some human patients that are treated with $\mathrm{rCaEPO}$, but there is still no evidence that support this in animals. Thus, there is disagreement on whether it is preferable to improve anemia partially or completely to avoid adverse effects like cardiovascular events, coagulation abnormalities and metabolic complications related to the use of these drugs, their dose and increased erythrocyte production and hemoglobin as a direct consequence (39). Respected to animal patients it is not clear whereas the complete correction of anemia represents a negative effect on CKD.

Other methods have shown interesting results in correcting anemia caused by CKD. Erythropoietin gene therapy has proven to be able to correct anemia in mice with induced anemia $(42,43)$. The peginesatide is a synthetic peptide that is not homologous to human erythropoietin, representing an absence of cross-reaction and production of anti-EPO (39). However, this drug has not been demonstrated superiority in the control of anemia, compared with the other drugs discussed above (44).

\section{Based therapy in Mesenchymal Stem Cells}

Based therapy in mesenchymal stem cells (MSC) offered protection in different forms of acute kidney injury in humans (45) and there is good evidence of the positive effects of MSCs in reducing the loss of function of kidney in the early stages of CKD (46). Therapy with MSC has particular functions related to the release of growths factors and cytokines with a paracrine action $(47,48)$. Bi et al (49) demonstrated in a murine model of acute kidney injury that administration of conditioned medium derived from bone marrow mesenchymal stem cells (CM-MSC) increased the survival time and decreases progression of renal injury. The protective effect of CM-MSC apparently are related to the action of pro-angiogenic factors such as vascular endothelial growth factor (VEGF), hepatocyte growth factor (HGF) and insulin growth factor (IGF) (50). Exosomes and microvesicles may have a similar effect $(51,52)$.

The research developed by Van Koppen and colleagues (53) found a significant decrease in systolic blood pressure in rats with induced CKD treated with CM-MSC compared to the group of rats that not receiving CM-MSC $(146 \pm 17$ vs 163 $\pm 21 \mathrm{mmHg} ; \mathrm{p}<0.05)$. They also found a decrease in proteinuria in rats with $\mathrm{CKD}$ receiving CM-MSC $(\mathrm{p}=0.007)$. However, they found no difference in renal clearance of creatinine and urea. In contrast, plasma creatinine in rats that did not receive 
CM-MSC was always higher compared with the group receiving treatment with CM-MSC $(p<0.05)$. The most important result of their research was that the higher percentage of glomerular endothelial cells present in rats receiving $\mathrm{CM}-\mathrm{MSC}$ and rats that did not receive CM-MSC, presented a percentage of 31 and $26 \%$ of not sclerotic glomeruli respectively. Interstitial fibrosis and tubular atrophy was lower due to decreased deposition of collagen type I and III in rats receiving CM-MSC demonstrating that repeated administration of $\mathrm{CM}-\mathrm{MSC}$ as rescue intervention of kidney function is probably due to an increase in long-term endothelial regeneration and recovery.

In summary, this novel treatment could slow down the loss of glomeruli, decrease fibrosis and alterations in glomerular function. As well as help in adjusting changes in vascular pressure, considering this latter like one important factors for life expectancy of patients with CKD and impacting the velocity of degeneration and the associated clinical signs. Furthermore, it should be necessary to review more investigation in the future to assess the impact on pets with diseases of natural progression and the evaluation of large cohorts of patients could be of help to determine the impact on life expectancy and clinical usefulness in reducing the progression of CKD and recognize the real effect of CM-MSC.

\section{Based therapy in Electroporation of Plasmid Growth Hormone}

CKD in humans can affect growth hormonerelease hormone; growth hormone; insulinlike growth factor I axis (GHRH/GH/IGF-I) (54, 55), which may affect disease progression and cell metabolism. Although little research exist in veterinary medicine about the axis (GHRH/ $\mathrm{GH} / \mathrm{IGF}-\mathrm{I}$ ) in CKD of natural progression; gene therapy based in plasmids growth hormone is a possible treatment in canine and cats, mainly for its influence on bone metabolism, proteins and glucose (56). GH and their mediator, IGF-I are growth regulators and maintain homeostasis in body weight and renal function. Some changes seen in patients with CKD are caused by the imbalance of the (GHRH/GH/IGF-I) axis $(57,58)$.

Therapy with GH produces a positive anabolic effect and helps maintain a physiological balance of renal function in people with $\operatorname{CKD}(59,60)$. Electroporation (EP) is a very important technique in gene therapy because it allows a single dose with a long duration. This is a key factor to commensurate the impact of this type of drugs on the commodity of patients and owners that have complications receiving the medication or when owners cannot administer medication at intervals or schedules required by the clinician. The study published by Brown and colleagues (61) developed a multicenter control group study using gene therapy with GH and EP in dogs and cats with CKD as an animal model for CKD on humans. Acording to the results, they found out an increase in survival time and increased body weight and muscle mass. In addition, health-related quality of life was improved in the group of patients treated with GHEP. Particularly dogs treated with GHEP increased physical activity and appetite, compared with the control group $(\mathrm{p}=0.001)$.

At the biological level increased blood-levels of IGF-I in patients treated with GHEP slightly improved hematologic parameters were found. The main reason for using these therapeutic options is to increase synthesis and bioavailability of IGF-I. This study suggests that clinical intervention with GHEP can preserve kidney function and reduce the negative effects of CKD in the health-related quality of life, especially decreasing the amount of times that the drug must be administered and the need for recurrent hospitalization. Furthermore, research are needed for recognize the long-term impact in the disease.

\section{Tanshinone IIA as an alternative therapeutic option in CKD}

Red sage (Salvia miltiorrhiza) is a perennial plant, valued as one of the most important ancient medicines, describe in the Shen-Nung's PenTs'ao book of herbal medicine and agriculture of traditional Chinese medicine (62). Their chemical component (salvianolic acid, Dihidrotanshinone, Tanshinone I and Tanshinone IIA) has been also studied for years, especially for its effects against cancer and degenerative inflammatory diseases. Tanshinone IIA is the most abundant chemical component of the rhizome of the plant and its particularly evaluated for the treatment of arthritis, hepatitis, acute coronary syndrome, neuropathic pain, bone tumors and Alzheimer's 
disease (63-67). This molecule has antioxidant properties and protects against oxidative stress. But also, chemical component alows vasodilation by stimulating the release of Nitrous Oxide (NO) on consequent decrease in blood pressure in animal models of hypertension and with the same protective effects in people with diabetic nephropathy $(68,69)$.

The investigation published by Ahn et al (70) evaluated the influence of Tanshinone IIA in renal function, proteinuria and expression of angiotensin II (Ang II), transforming growth factor beta I (TGF-B1) and type IV collagen in an experimental murine model. Taking as a hypothesis the harmful relationship of the Ang II, TGF-B1 and collagen type IV in the pathogenesis of CKD and the development of glomerulosclerosis (GC), the results found that prolonged use of Tanshinone IIA (8 to 12 weeks), the proteinuria significantly decreased. Moreover, glomerulosclerosis evaluated histologically was more widespread in the group that cannot receive Tanshinone IIA $(3.2 \pm 0.2$ vs $2.1 \pm 0.1 ; \mathrm{p}<0.05)$. The protein expression analysis showed that the use of Tanshinone IIA prevents expression of (TGF-B1) $(33.8 \pm 4.8$ vs $20.2 \pm 2.9 ; \mathrm{p}<0.05)$. In contrast, the expression of type IV collagen in patients receiving Tanshinone IIA was significantly decreased (0.45 \pm $0.04 \mathrm{ng} / \mathrm{ml}, \mathrm{p}<0.05$ ).

In conclusion these results could be demonstrate that Tanshinone IIA decreases the progression of CKD, attenuating the pathological structural manifestation of chronic kidney disease and the progressive characteristic fibrosis. Furthermore, these results must be interpreted with caution and more investigations are expected with other animal models to deeply assess their true benefit in CKD of natural progression. Nevertheless, the reason for exposing here this plant is mainly the approach of a possible integration between modern medicine and traditional medicine, due the potential beneficial impact of combined treatment with standard therapy. Taking into account, that actually different efforts exist to create the critical approach that aims to integrate alternative therapies for CKD, but with evidencebase medicine and long-term results.

\section{Thinking outside the box "ACE inhibitor"}

In addition to the nutritional intervention and its benefits in renal protection and improvement of the health-related quality of life in dogs and cats with $\mathrm{CKD}$, of all drugs studied in the last decade, angiotensin converting enzyme inhibitors (ACEI's) have shown to be statistically the most effective. An early research with these molecules in humans was done by Lewis and colleagues (71), which evaluated the efficacy of ACEI's in treating diabetic nephropathy and initially, they efficacy was attributed to the antihypertensive effects "hemodynamic effects". However, at the time, it is well-know that their effects are not restricted to pressure. The ACEI's are frequently used in veterinary medicine for the treatment of heart failure in dogs and cats $(72,73)$. These molecules are also key drugs in CKD in dogs, cats and humans.

The Renin-angiotensin-aldosterone system (RAAS), partially blocked by these ACEI's drugs, is traditionally known as an endocrine axis of control of water and salt reabsorption, commonly characterized by initial activation of renin in the kidney. Nevertheless, the production of all components of the RAAS can be synthesized in the absence of this release of renin by the kidney and could be synthesized in any organ, especially the heart, lung, brain, placenta, pancreas, adipose tissue and vascular bed (74). The difference between systemic RAAS and renal RAAS activation has a clinical importance related to ACEI's drugs use, specifically in the inhibition of tissue and plasmatic ACE. In the latter, inhibition is much lower and was confirmed by investigations of Lavoie et al (74). Moreover, the activity and concentrations of $\mathrm{ACE}$, Angiotensin II and its receptor (AT-1) in the kidney are different from other organs. The renin is synthesized by cells of the juxtaglomerular cortex; angiotensinogen is secreted in the proximal tubule cells, ACE is found in large quantities in the brush border of the cell membranes of the proximal tubule and this promotes rapid conversion and levels of Angiotensin II (Ang II) rise about 1000 times more than in the general circulation $(74,75)$.

Angiotensin converting enzyme (ACE), not only converts Ang I to Ang II, also degrades bradykinin, with important effects on natriuresis and control of the balance between vasoconstriction and vasodilatation (76). Furthermore, Ang II is also converted by specific tissue enzymes (chymase, cathepsin G and chymostatin) (77). Angiotensin II is the most powerful end effector systems, which control blood pressure through the reabsorption 
of sodium and water, stimulating receptors (AT-1 and AT-2) in the kidney or indirectly stimulating the production of aldosterone by the adrenal glands. Although ACEI's inhibit the conversion of Ang I to Ang II, these do not inhibit conversion mechanisms not ACE (chymase, cathepsin G and chymostatin) and then, Ang II levels cannot completely be suppressed. This are defined as "angiotensin breakthrough". Lantis and colleagues (77) found that aldosterone levels do not appear to decrease in patients treated with ACEI's, this also known as aldosterone breakthrough. The implications of both "breakthroughs" in the pathophysiology of cardiovascular and kidney disease as we knew are enormous and perhaps revolutionary.

Exposures to high and prolonged concentrations of aldosterone result in sodium retention, expansion of extracellular volume and fibrosis contributing to endothelial damage (75). Possible options to avoid this breakthrough are the use of drugs as Ang II receptor blockers "ARBs", aldosterone receptor blockers or direct renin inhibitors (77). Regardless of the etiology of CKD, glomerulosclerosis and interstitial fibrosis are characteristic pathologic findings in the final stages of CKD (IRIS III-IV) (78). The RAAS activation has proven to be the cause of progressive hypertension, fibrosis, tubulointerstitial injury and increased pro-inflammatory cells in the kidney in different species including dogs and cats (74). Specifically Ang II increases the formation of Tissue Growth Factor type B1 (TGF-B1) a fibrogenic cytokine responsible not only for the increase in the synthesis but also the decreased degradation of extracellular matrix (ECM) by the expression of fibronectin, laminin, collagen, proteoglycans and entactines that develop interstitial fibrosis.

The (TGF-B1) also stimulates contraction of vascular smooth muscle and mesangial cells, the latter involved in the development of glomerulosclerosis (11). Serpin E1 (inhibitor of plasminogen activator type 1 or PAI-1) are directly related to the pathophysiology of thromboembolic events and arterial fibrotic; it's a protein responsible for preventing fibrinolysis, by inhibiting urokinase and tissue plasminogen activator (uPA and tPA). The production of this protein increases due to the Ang II (79) causing inhibition of proteases that regulate the formation of ECM, increasing progression of glomerulosclerosis, tubulointerstitial fibrosis and increased inflammatory cells in kidney, especially macrophages (80). Another mechanism that increases the formation of ECM is the inability to self-regulate glomerular pressure. In physiological situations, variations in systemic blood pressure have little influence on glomerular arteriolar pressure, as CKD progresses this ability is lost, leaving the glomeruli exposed to very marked changes in systemic pressure and then distend the glomerular capillaries with subsequent stimulation of mesangial cell and production of TGF-B1. Thus, CKD progresses to chronic renal failure (CRF), but the authors recommend that indiscriminately both terms have been used to refer to the same concept. There may be chronic kidney disease without renal failure. However, renal failure cannot exist without chronic or acute kidney disease.

The ACEI's lower blood pressure experimentally when inhibit Ang II production and help decreasing the formation of ECM (production of TGF-B1) and these effects have been study in rodent models. One research develop by Brown and colleagues (81) started administrating Benazepril $(0.25 \mathrm{mg} /$ $\mathrm{kg}$ V.O SID) for 6.5 months to cats with induced CKD, showing a decrease in glomerular pressure ( $<12-14 \mathrm{mmHg})$. The relation between afferent arteriolar and efferent arteriolar resistance decreased in the cats receiving Benazepril. Other studies also confirmed these results (82). In dogs with induced CKD treated with ACEI's, experimentally a decrease of $30 \%$ in efferent arteriolar resistance was evident, while the afferent remained unchanged (83).

Hypertension is associated with kidney damage and progressive loss of kidney filtration in people (44). Although not widely investigated in dogs and cats, there are enough reasons to extrapolate this from humans to pets with CKD. Considering the above, the use of ACEI's as hypotensive and antisclerotic drug can benefit patients with CKD. However, the decrease in blood pressure is not evident in a percentage of the population by the breakthrough of angiotensin, the decreased plasma renin activity in some patients and high circulating levels of sodium (78). The decrease in blood pressure is dose dependent especially in cats. Using ACEI's as Enalapril to $0.25 \mathrm{mg} /$ $\mathrm{kg}$ once a day, the blood pressure decrease $23 \%$, whereas if the same dose is administered twice a day, blood pressure decreases near $41 \%$ (84). The calcium channel blockers such as amlodipine, belonging to the dihydropyridine drugs, is the first 
choice in the treatment of high blood pressure in cats and can be used in a joint with ACEI's therapy to treat patients with uncontrolled hypertension and CKD (85).

Proteinuria is caused by alterations in the permeability and selectivity of the glomerular membrane, such as mechanical factors (excessive pressure), incomplete coverage of the glomerular podocytes caused by hypertrophy through toxins or immune complexes in the surface. The ACEI's are protective for future increases of proteinuria, despite the molecular and cellular mechanisms under its antiproteinuric effect at the time cannot yet fully elucidated. Several hypotheses exist and one is the molecular modulation of podocytes. Podocytes are visceral glomerular cells, lining the outside of the glomerular basement membrane; this being the final barrier to the loss of protein $(86,87)$. The author Asanuma and colleagues $(86)$ recently reviewed the importance of podocytes in the progression of damage, glomerulosclerosis and progression of renal disease. The first decrease in proteinuria appears to be development by decreasing blood pressure $(78,88)$.

Enalapril and benazepril has been the most ACEI drugs documented to decrease proteinuria. Urinary Protein creatinine ratio (UP/C) decreases approximately 4.2 times in patients treated with Enalapril vs 1.9 times in feline patients treated with placebo $(83,88)$. In summary, the use of ACEI's in patients with CKD modulate blood pressure, renal excretion of protein and slows the rise on blood creatinine levels. Moreover, reduction of the incidence of decompensation in the final stages of the disease is one of the critical benefit $(78,88$, 89). The effectiveness is dependent when ACEI treatment starts (90). Overall, it has been admitted that the administration of ACEI's early in the course of CKD improve the antihypertensive, antiproteinuric and antiesclerotic effects $(11,75,90)$.

The ACEI's has been shown to increase survival time by $36 \%$ in patients with CKD (88). Moreover, changes in diet and simultaneously medication with ACEI's produces an increase of 53\% life expectancy (73). CKD has the consequences that decrease the concentration of plasma proteins due to their loss through the affected glomeruli (90) and the use of ACEI's showed that in cats with CKD also contributes to maintaining stable levels of protein in plasma. However, further research is recommended to interpret some missing issues of the mechanism of action of these drugs. Finally, it is unquestionable that the ACEI's remain the critical drugs of choice in CKD for dogs and cats.

\section{Conclusions}

After discussing about different treatment options, it is clear that further research is needed to develop better treatments and optimize the use of current therapy. Furthermore, the integrated management of proteinuria, clinical symptoms and the changes in biosynthesis, are unquestionably, factors influencing the healthrelated quality of life, survival time and disease progression. Recommended here, treatments are part of that integrated management, although individually reported each effects on the CKD, the joint use of these therapies and drugs may have superior effects. Nevertheless, it is important to recommend that every patient is different, their status, initial condition, the variability of disease and its approach are factors to be necessarily taken into account and the need to treat several patients in a specific way not will necessarily be the same in another.

\section{Acknowledgements}

The authors declare no conflicts of interest.

\section{References}

1. Polzin DJ. Chronic kidney disease in small animals. Vet Clin North Am Small Anim Pract 2011; 41(1): 15-30.

2. Bartges JW. Chronic kidney disease in dogs and cats. Vet Clin North Am Small Anim Pract 2012; 42(4): 669-92.

3. Polzin D. Chronic kidney disease. In: Bartegs J, Polzin DJ, eds. Nephrology and urology of small animals. Ames : Wiley Blackwell, 2011: 431-71.

4. Crook E, Washington D, Flack J. Screening and prevention of chronic kidney disease. J Natl Med Assoc 2002; 94: 55S-62S.

5. Ettinger SJ, Feldman EC. Textbook of veterinary internal medicine: diseases of the dog and cat. St. Louis : Elsevier Health Sciences, 2009.

6. Sparkes AH. Feeding old cats: an update on new nutritional therapies. Top Companion Anim Med 2011; 26(1): 37-42. 
7. Kopple JD. Effect of nutrition on morbidity and mortality in maintenance dialysis patients. Am J Kidney Dis 1994; 24(6): 1002-9.

8. Parker VJ, Freeman LM. Association between body condition and survival in dogs with acquired chronic kidney disease. J Vet Intern Med 2011; 25(6): 1306-11.

9. Roudebush P, Polzin DJ, Adams LG, Towell TL, Forrester SD. An evidence-based review of therapies for canine chronic kidney disease. J Small Anim Pract 2010; 51(5): 244-52.

10. Roudebush P, Polzin DJ, Ross SJ, Towell TL, Adams LG, Dru Forrester S. Therapies for feline chronic kidney disease. What is the evidence? J Feline Med Surg 2009; 11(3):195-210.

11. Lee SY, Kim SI, Choi ME. Therapeutic targets for treating fibrotic kidney diseases. Transl Res 2015;165(4): 512-30.

12. Richardson PE. David Sackett and the birth of evidence based medicine: how to practice and teach EBM. BMJ 2015; 350: h3089.

13. Elliott D. Nutritional management of chronic renal disease in dogs and cats. Vet Clin North Am Small Anim Pract 2006; 36:1377-84.

14. Elliott DA. Nutritional considerations for the dialytic patient. Vet Clin North Am Small Anim Pract 2011; 41(1): 239-50.

15. Laflamme DP. Pet food safety: dietary protein. Top Companion Anim Med 2008; 23(3): 154-7.

16. Larsen JA, Parks EM, Heinze CR, Fascetti AJ. Evaluation of recipes for home-prepared diets for dogs and cats with chronic kidney disease. J Am Vet Med Assoc 2012; 240(5): 532-8.

17. Chi H, Lin X, Huang H, Zheng X, Li T, Zou Y. Omega-3 fatty acid supplementation on lipid profiles in dialysis patients: meta-analysis. Arch Med Res 2014; 45(6): 469-77.

18. Tayebi Khosroshahi H, Mousavi Toomatari SE, Akhavan Salamat S, Davar Moin G, Najafi Khosroshahi S. Effectiveness of omega-3 supplement on lipid profile and lipid peroxidation in kidney allograft recipients. Nephrourol Mon 2013; 5(3): 822-6.

19. Hoogeveen EK, Geleijnse JM, Kromhout D, et al. Effect of omega-3 fatty acids on kidney function after myocardial infarction: the Alpha Omega Trial. Clin J Am Soc Nephrol 2014; 9(10): 1676-83.

20. Modaresi A, Nafar M, Sahraei Z. Oxidative stress in chronic kidney disease. Iran $\mathrm{J}$ Kidney Dis 2015; 9(3): 165-79.

21. Yu S, Gross K, Allen T. A renal food sup- plemented with vitamins $\mathrm{E}$ and $\mathrm{C}$ and beta-carotene reduces oxidative stress and improves kidney function in client-owned dogs with stages 2 or 3 kidney disease. In: 16th ECVIM-CA Congress. Amsterdam, 2006.

22. Brown SA. Oxidative stress and chronic kidney disease. Vet Clin North Am Small Anim Pract 2008; 38(1): 157-66.

23. Klein BG, ed. Cunningham's textbook of veterinary physiology. $5^{\text {th }}$ ed. St. Louis : Elsevier Saunders, 2013.

24. Nelson RW, Couto CG, eds. Small animal internal medicine. 5th ed. St. Louis : Elsevier, 2014.

25. Hill RC. Conference on "Multidisciplinary approaches to nutritional problems". Symposium on "Nutrition and health". Nutritional therapies to improve health: lessons from companion animals. Proc Nutr Soc 2009; 68(1): 98-102.

26. Cortadellas O, Fernandez del Palacio MJ, Talavera J, Bayon A. Calcium and phosphorus homeostasis in dogs with spontaneous chronic kidney disease at different stages of severity. $\mathrm{J}$ Vet Intern Med 2010; 24(1): 73-9.

27. Lippi I, Guidi G, Marchetti V, Tognetti R, Meucci V. Prognostic role of the product of serum calcium and phosphorus concentrations in dogs with chronic kidney disease: 31 cases (2008-2010). $\mathrm{J}$ Am Vet Med Assoc 2014; 245(10): 1135-40.

28. King JN, Delport PC, Luus HG, Erasmus HL, Barnes PM, Speranza C. Efficacy and acceptability of the new oral phosphate binder Lenziaren $((\mathrm{R}))$ in healthy cats fed a renal diet. J Vet Pharmacol Ther 2015; 38(3): 278-89.

29. Hostutler RA, DiBartola SP, Chew DJ, et al. Comparison of the effects of daily and intermittent-dose calcitriol on serum parathyroid hormone and ionized calcium concentrations in normal cats and cats with chronic renal failure. $\mathrm{J}$ Vet Intern Med 2006; 20(6): 1307-13.

30. DiBartola SP. Chronic renal failure. In: Polzin DJ, ed. Canine and feline nephrology and urology. 2nd ed. St. Louis : Elsevier Saunders, 2011: 145-96.

31. Weir MR, Bakris GL, Bushinsky DA, Mayo MR, Garza D, Stasiv Y, et al. Patiromer in patients with kidney disease and hyperkalemia receiving RAAS inhibitors. N Engl J Med 2015; 372(3): 211-21.

32. Segev G, Fascetti AJ, Weeth LP, Cowgill LD. Correction of hyperkalemia in dogs with chronic kidney disease consuming commercial renal therapeutic diets by a potassium-reduced home-pre- 
pared diet. J Vet Intern Med 2010; 24(3): 546-50.

33. Eatroff $\mathrm{AE}$, Langston $\mathrm{CE}$, Chalhoub $\mathrm{S}$, Poeppel K, Mitelberg E. Long-term outcome of cats and dogs with acute kidney injury treated with intermittent hemodialysis: 135 cases (1997-2010). J Am Vet Med Assoc 2012; 241(11): 1471-8.

34. Mazzaferro EM. Blackwell's five-minute veterinary consult clinical companion: small animal emergency and critical care. Ames, Iowa : Wiley, 2011.

35. Silverstein D, Hopper K. Small animal critical care medicine. 2nd ed. St. Louis : Elsevier Health Sciences, 2014.

36. Gotloib L, Silverberg D, Fudin R, Shostak A. Iron deficiency is a common cause of anemia in chronic kidney disease and can often be corrected with intravenous iron. J Nephrol 2006; 19: 161-7.

37. Horl W. Iron therapy for renal anemia: how much needed, how much harmful? Pediatr Nephrol 2007; 22: 480-9.

38. Robinson B, Artz A, Culleton B, Critchlow C, Sciarra A, Audhya P. Prevalence of anemia in the nursing home: contribution of chronic kidney disease. J Am Geriatr Soc 2007; 55: 1566-70.

39. Drueke TB. Anemia treatment in patients with chronic kidney disease. N Engl J Med 2013; 368(4): 387-9.

40. Bodles-Brakhop A, Brown P, Pope M, Draghia-Akli R. Double-blinded, placebo-controlled plasmid GHRH trial for cancer-associated anemia in dogs. Mol Ther 2008; 16: 862-70.

41. Randolph J, Scarlett J, Stokol T, MacLeod J. Clinical efficacy and safety of recombinant canine erythropoietin in dogs with anemia of chronic renal failure and dogs with recombinant human erythropoietin-induced red cell aplasia. J Vet Intern Med 2004; 18: 81-91.

42. Lu X, Zhou A, Jin C. [The effects of electroporation-mediated erythropoietin (EPO) gene transfer into skeleton muscle on renal anemia]. Zhonghua Yi Xue Za Zhi 2000; 80(3): 222-5.

43. Lin RZ, Dreyzin A, Aamodt K, et al. Induction of erythropoiesis using human vascular networks genetically engineered for controlled erythropoietin release. Blood 2011; 118(20): 5420-8.

44. Palit S, Chonchol M, Cheung AK, Kaufman J, Smits G, Kendrick J. Association of BP with death, cardiovascular events, and progression to chronic dialysis in patients with advanced kidney disease. Clin J Am Soc Nephrol 2015; 20(6): 934-40.

45. Imai N, Kaur T, Rosenberg ME, Gupta S. Cellular therapy of kidney diseases. Semin Dial
2009; 2(6): 29-5.

46. Choi SJ, Kim JK, Hwang SD. Mesenchymal stem cell therapy for chronic renal failure. Expert Opin Biol Ther 2010; 10(8): 1217-26.

47. Bianchi F, Sala E, Donadei C, Capelli I, La Manna G. Potential advantages of acute kidney injury management by mesenchymal stem cells. World J Stem Cells 2014; 6(5): 644-50.

48. Humphreys BD, Bonventre JV. Mesenchymal stem cells in acute kidney injury. Annu Rev Med 2008; 59: 311-25.

49. Bi B, Schmitt $R$, Israilova $M$, Nishio $H$, Cantley LG. Stromal cells protect against acute tubular injury via an endocrine effect. J Am Soc Nephrol 2007; 18(9): 2486-96.

50. Zarjou A, Kim J, Traylor AM, et al. Paracrine effects of mesenchymal stem cells in cisplatin-induced renal injury require heme oxygenase-1. Am J Physiol Renal Physiol 2011; 300(1): F254-62.

51. Bruno S, Grange C, Collino F, et al. Microvesicles derived from mesenchymal stem cells enhance survival in a lethal model of acute kidney injury. PLoS One 2012; 7(3): e33115 (11pp). http://journals.plos.org/plosone/article / file?id=10.1371/journal.pone.0033115\&type $=$ printable

52. Camussi G, Deregibus MC, Bruno S, Cantaluppi V, Biancone L. Exosomes/microvesicles as a mechanism of cell-to-cell communication. Kidney Int 2010; 78(9): 838-48.

53. van Koppen A, Joles JA, van Balkom BW, et al. Human embryonic mesenchymal stem cell-derived conditioned medium rescues kidney function in rats with established chronic kidney disease. PLoS One 2012; 7(6) : e38746 (12 pp). http:/ /journals.plos.org/plosone/article/file?id=10.1371/ journal.pone.0038746\&type $=$ printable

54. Mahesh S, Kaskel F. Growth hormone axis in chronic kidney disease. Pediatr Nephrol 2008; 23(1): 41-8.

55. Mak RH, Cheung WW, Roberts CT, Jr. The growth hormone-insulin-like growth factor-I axis in chronic kidney disease. Growth Horm IGF Res 2008; 18(1): 17-25.

56. Wuhl E, Schaefer F. Effects of growth hormone in patients with chronic renal failure: experience in children and adults. Horm Res 2002; 58(Suppl 3): 35-8.

57. Cayir A, Kosan C. Growth hormone therapy in children with chronic renal failure. Eurasian J Med 2015; 47(1): 62-5. 
58. Mak R, Cheung W, Roberts C. The growth hormone-insulin-like growth factor-I axis in chronic kidney disease. Growth Horm IGF Res 2007; 18: 17-25.

59. Bubber P, Sharma A, Chauhan A, Bansal DD. Effect of growth hormone on plasminogen activator and inhibitor activity in rat. Indian $\mathrm{J}$ Clin Biochem 2013; 28(2): 193-6.

60. Wuhl E, Schaefer F. Effects of growth hormone in patients with chronic renal failure: experience in children and adults. Horm Res 2002; 58(Supp1 3): 35-8.

61. Brown P, Bodles-Brakhop A, Pope M, Draghia-Akli R. Gene therapy by electroporation for the treatment of chronic renal failure in companion animals. BMC Biotechnol 2009; 9(1): e4 (13 pp). https:/ / bmcbiotechnol.biomedcentral.com/ track/pdf/10.1186/1472-6750-9-4?site=bmcbiotechnol.biomedcentral.com

62. Luo Q, Liu CH, Gu M. [Recording of classical prescriptions and materia medica in the Han Dynasty]. Zhonghua Yi Shi Za Zhi 2010; 40(6): 376-8.

63. Zhang XZ, Qian SS, Zhang YJ, Wang RQ. Salvia miltiorrhiza: a source for anti-Alzheimer's disease drugs. Pharm Biol 2016; 54(1): 18-24.

64. Ren BX, Ji Y, Tang JC, et al. Effect of Tanshinone IIA intrathecal injections on pain and spinal inflammation in mice with bone tumors. Genet Mol Res 2015; 14(1): 2133-8.

65. Tang J, Zhu C, Li ZH, et al. Inhibition of the spinal astrocytic JNK/MCP-1 pathway activation correlates with the analgesic effects of tanshinone IIA sulfonate in neuropathic pain. J Neuroinflammation 2015; 12(1): e57 (12 pp).

https://jneuroinflammation.biomedcentral.com/ track/pdf/10.1186/s12974-015-0279-7?site=jneuroinflammation.biomedcentral.com

66. Hu H, Zhai C, Qian G, et al. Protective effects of tanshinone IIA on myocardial ischemia reperfusion injury by reducing oxidative stress, HMGB1 expression, and inflammatory reaction. Pharm Biol 2015; 53(12): 1752-82.

67. Xia T, Wu T, Ren Y, Wang Z, Wu R. [Tanshinone attenuates myocardial injury via activating JAK2/STAT1 pathway in a murine model of viral myocarditis]. Zhonghua Xin Xue Guan Bing Za Zhi 2015; 43(2): 167-72.

68. Kim DD, Sanchez FA, Duran RG, Kanetaka T, Duran WN. Endothelial nitric oxide synthase is a molecular vascular target for the Chinese herb Danshen in hypertension. Am J Physiol Heart
Circ Physiol 2007; 292(5): H2131-7.

69. Kim SK, Jung KH, Lee BC. Protective effect of Tanshinone IIA on the early stage of experimental diabetic nephropathy. Biol Pharm Bull 2009; 32(2): 220-4.

70. Ahn YM, Kim SK, Lee SH, et al. Renoprotective effect of Tanshinone IIA, an active component of Salvia miltiorrhiza, on rats with chronic kidney disease. Phytother Res 2010; 24(12): 1886-92.

71. Lewis EJ, Hunsicker LG, Bain RP, Rohde RD. The effect of angiotensin-converting-enzyme inhibition on diabetic nephropathy. The Collaborative Study Group. N Engl J Med 1993;329(20):1456-62.

72. Atkins C, Bonagura J, Ettinger S, et al. Guidelines for the diagnosis and treatment of canine chronic valvular heart disease. J Vet Intern Med 2009; 23(6): 1142-50.

73. Martignoni L, King JN, Pouchelot JL, Berres M. The effect of benazepril on survival times and clinical signs of dogs with congestive heart failure: results of a multicenter, prospective, randomized, double-blinded, placebo-controlled, long-term clinical trial. J Vet Cardiol 1999; 1(1): 7-18.

74. Lavoie JL, Sigmund CD. Minireview: overview of the renin-angiotensin system: an endocrine and paracrine system. Endocrinology 2003; 144(6): 2179-83.

75. Kim S, Iwao H. Molecular and cellular mechanisms of angiotensin II-mediated cardiovascular and renal diseases. Pharmacol Rev 2000; 52(1): 11-34.

76. Regulski M, Regulska K, Stanisz BJ, et al. Chemistry and pharmacology of angiotensin-converting enzyme inhibitors. Curr Pharm Des 2015; 21(13): 1764-75.

77. Lantis AC, Ames MK, Atkins CE, DeFrancesco TC, Keene BW, Werre SR. Aldosterone breakthrough with benazepril in furosemide-activated renin-angiotensin-aldosterone system in normal dogs. J Vet Pharmacol Ther 2015; 38(1): 65-73.

78. Lefebvre HP, Toutain PL. Angiotensin-converting enzyme inhibitors in the therapy of renal diseases. J Vet Pharmacol Ther 2004; 27(5): 265-81.

79. Tiryaki O, Usalan C, Buyukhatipoglu H. Effect of combined angiotensin-converting enzyme and aldosterone inhibition on plasma plasminogen activator inhibitor type 1 levels in chronic hypertensive patients. Nephrology (Carlton) 2010; 15(2): 211-5.

80. Usalan C, Buyukhatipoglu H. A dynamic 
comparative study concerning the effects of angiotensin-converting enzyme inhibitors and aldosterone receptor blockers on the fibrinolytic system. Clin Appl Thromb Hemost 2008; 14(2): 203-9.

81. Brown SA, Brown CA, Jacobs G, Stiles J, Hendi RS, Wilson S. Effects of the angiotensin converting enzyme inhibitor benazepril in cats with induced renal insufficiency. Am J Vet Res 2001; 62(3): 375-83.

82. Watanabe T, Mishina M. Effects of benazepril hydrochloride in cats with experimentally induced or spontaneously occurring chronic renal failure. J Vet Med Sci 2007; 69(10): 1015-23.

83. Brown SA, Finco DR, Brown CA, et al. Evaluation of the effects of inhibition of angiotensin converting enzyme with enalapril in dogs with induced chronic renal insufficiency. Am J Vet Res 2003; 64(3): 321-7.

84. Uechi M, Imamoto S, Ishikawa Y. Dose-dependent inhibition of angiotensin converting enzyme by enalapril in cats. J Vet Med Sci 2002; 64(4): 385-7.

85. Huhtinen M, Derre G, Renoldi HJ, et al. Randomized placebo-controlled clinical trial of a chewable formulation of amlodipine for the treat- ment of hypertension in client-owned cats. J Vet Intern Med 2015; 29(3): 786-93.

86. Asanuma K. [The role of podocyte injury in chronic kidney disease]. Nihon Rinsho Meneki Gakkai Kaishi 2015; 38(1): 26-36.

87. Saurus P, Kuusela S, Lehtonen E, et al. Podocyte apoptosis is prevented by blocking the Toll-like receptor pathway. Cell Death Dis 2015; 6: e1752 (12 pp).

https: / / www.nature.com/articles / cddis2015125.pdf

88. Mizutani H, Koyama H, Watanabe $\mathrm{T}$, et al. Evaluation of the clinical efficacy of benazepril in the treatment of chronic renal insufficiency in cats. J Vet Intern Med 2006; 20(5): 1074-9.

89. He YM, Feng L, Huo DM, Yang ZH, Liao YH. Enalapril versus losartan for adults with chronic kidney disease: a systematic review and meta-analysis. Nephrology (Carlton) 2013; 18(9): 605-14.

90. King JN, Gunn-Moore DA, Tasker S, Gleadhill A, Strehlau G. Tolerability and efficacy of benazepril in cats with chronic kidney disease. J Vet Intern Med 2006; 20(5): 1054-64.

\title{
KRITIČEN PRISTOP K ALTERNATIVNI OBRAVNAVI KRONIČNE ODPOVEDI LEDVIC PSOV IN MAČK
}

\author{
J.M.Pérez, C.Alessi
}

Povzetek: Kronična odpoved ledvic (CKD - iz angl. chronic kidney disease) se pogosto pojavlja pri psih in mačkah katerekoli starosti, pogostejša je pri starih pacientih. Z različnimi oblikami bolezni in njihovimi raznolikimi hemodinamskimi in presnovnimi različicami se ukvarja veliko raziskav. Trenutno izboljšanje celostnega zdravljenja kronične odpovedi ledvic se osredotoča na upočasnitev napredovanja kliničnih simptomov bolezni, obstaja pa vedno več novih metod za ta način zdravljenja v nereferenčnih centrih. Cilj predlaganega kritičnega pristopa je zagotoviti celovito obravnavo kronične odpovedi ledvic ter izpostaviti nove načine zdravljenja, ki bi lahko izboljšali poseganje v zdravje psov in mačk s kronično odpovedjo ledvic in ponovno oceno uporabnosti nekaterih obstoječih zdravil.

Ključne besede: kronična odpoved ledvic; kardiorenalni sindrom; glomerulonefritis; pes; mačka 